\title{
Simbolismo de la lluvia en Álvaro Mutis ${ }^{1}$
}

\author{
Gerardo Castillo \\ Pontificia Universidad Católica del Perú \\ gerardocastillo1@yahoo.com

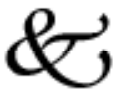 \\ Resumen
}

La lluvia es una imagen recurrente en la literatura en general y en la poesía en particular. Ella simboliza desde bucólicas imágenes de fertilidad hasta aciagos anuncios de muerte. El presente artículo busca dar cuenta del universo de significados al que está asociada la lluvia en la poesía de Álvaro Mutis. En la obra del autor, la lluvia es una de las manifestaciones del agua -junto a las figuras del río y el mar- y adquiere dos grandes polos de significación. La lluvia, de un lado, con su repetición incesante y monótona alcanza en Mutis a convertirse en metáfora del desgaste, de lo inevitable y de la nimiedad de la vida humana frente a los elementos naturales y a su propio destino. De otro lado, ella posee un valor liminal que diluye el tiempo y reconecta al yo con su pasado e intenta recomponer una identidad fragmentada. Esta doble condición de la lluvia, no solo la convierte en uno de los elementos temáticos centrales de la poesía de Mutis sino que la conectaría con la visión que el propio autor tiene del lenguaje poético. Para esta revisión me baso, muy especialmente, en los poemarios Los trabajos perdidos (1965) y Reseña de los hospitales de ultramar (1955) y en las reflexiones dejadas por Mutis en el Diario de Lecumberri (1960).

Palabras clave: Álvaro Mutis, poesía colombiana, imágenes poéticas, lluvia.

\begin{abstract}
In the present article the author looks at the world of meanings associated with the rain, a recurrent aymbol of fertility and death in the poetry of Alvaro Mutis. In this work, rain connects with water, the river and the sea, and expresses itsef as two great opposing poles. On one hand,
\end{abstract}

1 El presente artículo fue inicialmente concebido como parte del seminario sobre la obra de Álvaro Mutis dirigido por César Ferreira en la Universidad de Oklahoma, Norman, en el otoño del 2002 a propósito de la elección de Mutis como ganador del premio de internacional de literatura Neustadt 2002. Mi agradecimiento a César Ferreira y Rafael Anselmi por sus sesudos comentarios y puntuales correciones. 
the rain, with its unending and monotonous repetition is a metaphor: it means waste, inevitableness and the smallness of human life in front of the natural elements and its own destiny. On the other hand, rain possesses a liminal value that dilutes time and reconnects ego with his past and tries to recompose a fragmented identity. This twofold condition of the rain makes it one of Mutis's central elements of his poetry and connects it with his own vision of poetical language. The books Los trabajos perdidos (1965) and Reseña de los hospitals de ultramar (1955) and the poet's reflections in the Diario de Lecumberri (1960) have been used for this review.

Key words: Álvaro Mutis, Colombian Poetry, Poetic Images, Rain.

Banquo: It will rain tonight. First Murderer: Let it come down. [The First Murderer strikes out the light, while the others assault Banquo] William Shakespeare. Macbeth, act III, scene 3.

Volvió la lluvia. No volvió del cielo o del Oeste.

Ha vuelto de mi infancia.

Pablo Neruda. Odas elementales. Oda a la lluvia.

\section{Manifestaciones del agua}

El agua, bajo sus diversas formas, es una de las materias por excelencia de la que está compuesta la poesía de Álvaro Mutis. Ello, tanto porque el agua representa la vida misma y sus metamorfosis ${ }^{2}$ como por ser el medio a través del cual se desplaza Maqroll, el antihéroe de Mutis. Así, el río es elemento central en la obra del autor. De esta manera, en un tratamiento que nos recuerda a Un corazón en las tinieblas de Joseph Conrad o La vorágine de José Eustaquio Rivera, el río de La nieve del almirante representa la ruta, el viaje por sí mismo, el dejarse llevar por la corriente, la persecución inútil de un

2 Mutis, comunicación personal. 


\section{destino inevitable ${ }^{3}$. Además, él representa la arrolladora fuerza de la creciente:}

Al amanecer crece el río, retumban en el alba los enormes troncos que vienen del páramo.

Sobre el lomo de las pardas aguas bajan naranjas maduras, terneros con la boca bestialmente abierta, techos pajizos, loros que chillan sacudidos bruscamente por los remolinos [...] Llega la noche y el río sigue gimiendo al paso arrollador de su innumerable carga. ("La creciente", Summa... 21).

Ese es el río, encasillado por precipicios, que la poesía de Mutis lo asocia con la destrucción, pero también con la regeneración y la vi$\mathrm{da}^{4}$. El río que aún en sus más terribles remolinos ofrece un remanso o un madero al cual asirse en el presente de incesante fluir ${ }^{5}$.

Sin embargo, el río -como la vida misma y en una metáfora que se remonta quizás a Las coplas a la muerte de su padre de Jorge Manrique-finalmente se diluye en la inmensidad del mar ${ }^{6}$. El río, al encontrase con el mar en los miasmas del delta, grafica la disolución de la vida $^{7}$, el fin del viaje y la inutilidad de la lucha:

Una gran extensión de agua suavemente se mece en vastas regiones ofrecidas al sol de la tarde; aguas del gran río que luchan contra un mar en extremo cruel y helado, que levanta sus olas contra el cielo y a va a perderlas tristemente en la lodosa sabana del delta. ("Sonata", Summa... 89).

3 Hablando de su conexión con Conrad, Mutis afirma que lo que más le llama la atención en él es la noción de destino con la cual comulga completamente. "Esta implacable acción del destino sobre los seres, la inutilidad de tomar decisiones, de hacer propósitos.” (Sefamí 187).

4 Hoy ha llamado en mí/ el griterío de las aves que pasan en verde algarabía/ sobre las heladas espumas que bajan de los páramos,/ golpeando y sonando/ y arrastrando consigo la pulpa del café/ y las densas flores de los cámbulos. (“Exilio”, Summa... 85).

5 Hoy, se ha detenido dentro de mí,/ un espeso remanso hace girar,/ de pronto, lenta, dulcemente,/ rescatados en la superficie agitada de sus aguas,/ ciertos días, ciertas horas del pasado,/ a los que se aferra furiosamente/ la materia más secreta y eficaz de la vida./ Flotan ahora como troncos de tierno balso,/ la serena evidencia de fieles testigos/ y a ellos me acojo en este largo presente de exiliado. (“Exilio", Summa... 85).

6 En una suerte de oración fúnebre que evoca al mar, "[La muerte] Te abrirá los ojos a sus grandes aguas,/ te iniciará en su constante brisa de otro mundo." (“Amén”, Summa... 65).

7 No sería coincidencia, de esta manera, que la versión de la muerte de Maqroll en Un bel morir se produzca en los esteros: "Allí el río empezaba a confundirse con el mar y se extendía en un horizonte cenagoso y salino, sin estruendo ni lucha." (Empresas... 328). 
El mar además, cual experiencia sagrada, es la morada última a la que se remiten los sueños delirantes de enfermos y moribundos: "A menudo la pesadilla de la fiebre nos llevaba de la mano por caminos que conducían al fondo del mar, por entre la marea creciente, y allí, bestias sabias curaban nuestros males y nuestro cuerpo se endurecía para siempre como un lustroso coral en la primavera de las profundidades.” (“El hospital de la bahía”, Summa... 97-98).

Frente a las figuras del río -el agua en permanente discurrir- y el mar -la insondable inmensidad-se encuentra la del agua inmóvil que representa la inutilidad, el fin del viaje:

[...] si el tren ha ido descendiendo

hacia las ardientes sabanas en donde el aire se queda

detenido y las aguas exhiben una nata verdinosa, que denuncia su extrema quietud

y la inutilidad de su presencia [...] (“Breve poema de viaje”, Summa...

79).

Ella es el agua representada por las marismas, agua estancada y ponzoñosa, portadora de enfermedad y muerte ${ }^{8}$.

\section{La lluvia como permanente desgaste}

El universo de significados del agua, sin embargo, no está completo sin los elementos que componen la lluvia. En la obra de Mutis no se encuentra una imagen bucólica de la lluvia como sereno regocijo y símbolo de fertilidad. La primera figura que se nos ofrece es la de la lluvia destructiva, aquella presente en "los árboles quemados después de la tormenta” (“Sonata”, Summa... 87). Ella, es una lluvia incansable y carente de propósito, como la reflejada en este "Nocturno" de Los trabajos perdidos:

Esta noche ha vuelto la lluvia sobre los cafetales.

Sobre las hojas de plátano,

sobre las altas ramas de los cámbulos,

8 Otro ejemplo de la oposición entre vida y muerte, libertad e inmovilidad lo encontramos en "El hospital de la bahía": "El mar mecía su sucia charca gris y al subir la marea alcanzaba a entrar hasta nuestros lechos. iQué ironía el olor saludable de las grandes extensiones, moviéndose preso entre la inmundicia de nuestros males y la agridulce mueca de las medicinas!" (Summa... 97). 
ha vuelto a llover esta noche un agua persistente y vastísima que crece las acequias y comienza a henchir los ríos que gimen con su nocturna carga los lodos vegetales. La lluvia cae sobre el cinc de los tejados hasta dejarme en un crecer de las aguas sin sosiego, en la noche fresquísima que chorrea por entre la bóveda de los cafetos

y escurre por el enfermo tronco de los balsos gigantes. (Summa... 68, énfasis nuestro).

La lluvia, en su incesante reiteración, alimenta el desasosiego y se convierte en metáfora del desgaste de los elementos ${ }^{9}$, de la corrupción de la materia y de la futilidad de la vida humana:

Los días partidos por el pálido cuchillo de las horas, los días delgados como el manantial que brota de las minas, los días del poema... Cuánta vana y frágil materia preparan para las noches que cobija una Iluvia insistente sobre el cinc de los trópicos. Hierbas del dolor.

Todo aquí muere lentamente, evidentemente, sin vergüenza: hasta los rieles del tren se entregan al óxido y marcan la tierra con infinita ira paralela y dorada. (“Los trabajos perdidos”, Summa... 60, énfasis nuestro).

Es esta característica de la reiteración, lo que hace de la lluvia símbolo de lo inevitable, de lo consumado. Una idea del sin sentido que ya se encuentra elaborada en La nieve del almirante: "una caravana no simboliza ni representa cosa alguna...” (Mutis 2001, 30). En su terca insistencia, la lluvia no sólo la lava la materia, sino también, el espíritu $^{10}$, la memoria y la miseria humana ${ }^{11}$ :

9 Como reza en "El coche de segunda": "La pintura verde se había ido con las lluvias de tantos años y la madera había tomado ese color gris azulado propio del revés de las hojas del banano." (Summa... 102).

10 En este sentido, la lluvia anuncia la vivencia negativa del tiempo. Un tiempo que nos usa y desgasta. En una entrevista con Jorge Balza, Mutis expresa este sentido de la siguiente manera: Esto se refiere a que esta sensación perpetua de desastre que yo la he tenido desde pequeño, por haber tenido dos mundos que me fueron, profundamente, intensamente necesarios: por un lado Bélgica, la vida en Bélgica y en Europa, y después en la tierra caliente [...] Y después: la muerte de mi padre. Mi padre muere a los 33 años, cuando yo tenía nueve. Este suceso que fue la muerte de mi padre me dio una sensación de fracaso inmediato, de que todo se daña, de que todo se va entre las manos. (Balza 8).

11 Esta calidad redentora -o al menos purificadora de la miseria humana—de la lluvia es resaltada constantemente en el Diario de Lecumberri: 
La lluvia caía ya torrencialmente. Lavaba el piso del campo y saltaba entre el lodo fresco y humeante. Lavaba las paredes de tezontle, corría a torrentes sobre la placa que recuerda el asesinato de Madero, lavaba los brillantes abrigos de caucho de los guardias, la torre metálica del polígono, los patios, las cocinas. Insistente, reunida en alegres torrenteras, empezó a llevarse toda la miseria de nuestros días, toda la crueldad, el hambre, el delirio, la sorda y mezquina furia de los guardias. Todo se lo fue llevando la lluvia hasta que fuimos quedando sin otra cosa que nos separara del aire viajero que corre por entre las complicadas construcciones de Lecumberri, que el agua transparente que caía de lo más alto del cielo, del rincón en donde nos esperaba la libertad como una loba rabiosa que busca a sus hijos. (Diario de Lecumberri 28).

Pero la lluvia no es sólo símbolo, sino que ella actúa y al hacerlo se transforma en rito. En la introducción que hace de Los hospitales del ultramar, Octavio Paz llama la atención sobre el poema final, al que considera un treno a la muerte, que exige el rito, la forma, ante la desnudez final ${ }^{12}$. Precisamente, la eficacia de la lluvia, como todo rito, consiste en su exacta repetición hacia el infinito ${ }^{13}$. Es a través

Hablé con el mayor y no recuerdo ya muy bien lo que me dijo. Lo cierto es que ayer, cuando regresé del campo deportivo y empezaba a llover, lo vi encerrarse en su celda temeroso. Ya había olvidado el asunto. En la cárcel, cada cual tiene sobre sí un peso tal de angustia y desesperanza, que el dolor de los otros resbala como el agua sobre las plumas de los patos.

Después vino la lluvia y, con ella, en la noche, se lavaron de mi memoria todo el sufrimiento y todo el miedo que se pega a las paredes del penal y que nos sumen en su miserable sustancia. Cuando llamaron la lista a la mañana siguiente, una fresca llovizna seguía cayendo todavía perezosamente. (34).

12 [...] de la gran desnudez y, también del apogeo de la forma. Lujo y agonía: ceremonia de la catástrofe, rito del desastre. Todo, incluido la muerte, exige una liturgia. No hay mito, no hay fábula recreadora del mundo y, en una palabra, no hay poesía sin un rito. La poesía es liturgia: los momentos centrales del hombre -desde su nacimiento hasta su muerte-los prefigura y consagre el rito. El poema es una ceremonia fúnebre: la máscara solar del poeta esconde un rostro comido por la muerte. Triunfo de la apariencia, es decir, del espíritu humano que tiende siempre a encarnar, a manifestarse, a presentarse y, de este modo, a erigirse en monumento de sí mismo, de su poder y su ruina. Forma es vida. La falta de forma del mundo moderno es ausencia de verdadera vida. Eros y la muerte han huido del hombre -cuerpo deshabitado, cuerpo desalmado--. En nuestros días la misión del poeta consiste en convocar a los viejos poderes, revivir la liturgia verbal, decir la palabra de vida. (12).

13 A pesar de este elemento místico en la poesía de Mutis, ella no propone redención alguna sino la eterna comprobación de la futilidad de la vida humana, lo ilusorio de la felicidad y el decantamiento de la desesperanza (Hernández). 
de este ritual que la lluvia remite a una experiencia purificadora con lo primigenio:

En medio de la niebla caliente de los baños de vapor, entre los cuerpos lastimados y desnudos, envuelto en el perfume barato de los jabones y las cremas para rasurar, entre gritos y risas anónimos, ensordecido por el ruido del agua que cae y corre por el piso y ruge en los tubos, se recobra la libertad; una libertad aparente, falsa, es cierto, pero que renueva y fortalece nuestras fuerzas para resistir el peso de la prisión. Desnudos, sin uniforme, sin letras ni números, volvemos a tener nuestros nombres y hablar de nuestra vida de "afuera", de la gozosa materia de nuestros días de hombres libres, a la que nunca se alude en otro sitio de la prisión, para que no la absorba y contamine la fea grasa miserable que todo lo mancilla y enmohece y que en todo está presente. La corriente purificadora del agua y el vapor que brama al escaparse por las llaves, ahuyentan la humillante presencia del castigo. (Diario de Lecumberri 35).

Mientras como símbolo, la lluvia condensa los significados de corrupción de la materia y purificación del espíritu, como rito tiene la capacidad de actuar gracias a la repetición cíclica según normas establecidas.

\section{Recuperación de la memoria}

En la repetición se produce el conjuro que llama a la memoria ${ }^{14}$. A través de su reiteración la lluvia opera como ritual que suspende el ahora y permite un viaje hacia el pasado. La presencia de la lluvia en la poesía de Mutis no sólo remite a la corrupción y el desgaste. Ella posee un segundo polo positivo de significación que activa la memoria de los personajes. En Reseña de los hospitales de ultramar, una lluvia persistente que llama al recuerdo es parte del telón de fondo para un Maqroll en reposo. Mas no el reposo ansiado y reparador de quien espera el siguiente viaje, sino la parada última de quien ha llegado al final de sus días. Ya uno de los epitafios que abre el poemario nos lo advierte, en una descripción que bien podría ser de la prisión de

14 "iAh, esos nombres pronunciados de lecho en lecho como una letanía de lejanos recuerdos detenidos en el ebrio dintel de la infancia!” (El hospital de la bahía, Summa... 96). 
Lecumberri: "Los altos muros grises elevan su fábrica contra el cielo, anunciando la presencia consoladora de aquellos edificios hechos al dolor y antesala de la muerte." $(92)^{15}$.

La lluvia es el espacio liminal que suspende el presente y reconecta a los personajes de Mutis con su pasado e identidades fragmentadas. La lluvia logra salvar el tiempo y trae los recuer$\operatorname{dos}^{16}$ :

Ahora, de repente, en mitad de la noche

ha regresado la lluvia sobre los cafetales

y entre el vocerío vegetal de las aguas

me llega la intacta materia de otros días

salvada del ajeno trabajo de los años. ("Nocturno", Summa... 68)

Y es mediante los recuerdos que brevemente se recupera la infancia, el paraíso y la libertad perdidos:

[...] y olvido así quien soy, de dónde vengo,

hasta cuando una noche

comienza el golpeteo de la lluvia

y corre el agua por las calles en silencio

y un olor húmedo y cierto

me regresa a las grandes noches del Tolima (“Exilio”, Summa... 85).

La lluvia, como el vapor o el agua que cae de las duchas de la prisión de Lecumberri, juega con olvido y memoria. Vicariamente,

15 La introducción no podía ser más expresiva:

Los siguientes fragmentos pertenecen a un ciclo de relatos y alusiones tejidos por Maqroll El Gaviero en la vejez de sus años, cuando el tema de la enfermedad y de la muerte rondaba sus días y ocupaba buena parte de sus noches, largas de insomnio y visitadas de recuerdos.

Con el nombre de Hospitales de Ultramar cubría El Gaviero una amplia teoría de males, angustias, días en blanco en espera de nada, verguienzas de la carne, faltas de amistad, deudas nunca pagadas, semanas de hospital en tierras desconocidas curando los efectos de largas navegaciones por aguas emponzoñadas y climas malignos, fiebres de la infancia, en fin, todos esos pasos que da el hombre usándose para la muerte, gastando sus fuerzas y bienes para llegar a la tumba y terminar encogido en la ojera de su propio desperdicio. Ésos eran para él sus Hospitales de Ultramar. (93, énfasis nuestro).

16 Refiriéndose a la muerte de Rigoberto, un compañero de prisión, Mutis escribe que: "Nadie se apiadó de él, no volví a oír su nombre para nada. Solamente yo habré de recordarlo cada vez que un relámpago me despierte en medio de la noche, o que la lluvia caiga sobre mi vigilia de hombre libre." (Diario de Lecumberri 34). 
nos aleja por un instante del miserable presente y nos conecta con el pasado de un paraíso perdido de libertad ${ }^{17}$ :

Bajo la ducha se vuelven a cantar las canciones con las que amaron y viajaron, con las que gozaron y sufrieron los que una vez fueron libres. Ciertos nombres de mujer, ciudades, calles, sólo se escuchan en los bancos del vapor, en donde la niebla borra paredes y rejas y se pega al oscuro cemento haciéndolo impalpable e invisible. A mi lado, cuántas veces escucho una interminable evocación de circunstancias y lugares, de trozos de vida perdidos en un pasado ilusorio y por completo separado de nuestra vida presente. Nunca vemos los rostros, ni distinguimos los cuerpos que evocan con tan intensa y delirante devoción, una vida ajena a la miseria definitiva de Lecumberri. (Diario de Lecumberri 35, énfasis nuestro).

Frente a la miseria definitiva del presente, la lluvia pasajera nos opone al "recuerdo de esa breve felicidad/ ya olvidada/ y que fuera alimento de tantos años sin nombre." (“Sonata”, Summa... 87). Entre el agua y el vapor, las voces de los prisioneros tratan inútilmente de reconstruir pedazos de memorias e identidades, de alcanzar ese momento pasajero, fragmentado y borroso en el que son felices. En los baños el tiempo queda suspendido. Ese tiempo, que en la cárcel se encuentra fragmentado y pautado por una infinita rutina de deberes y órdenes, es la obsesión de la cual se busca escapar. El agua de la lluvia y la que cae de las duchas tiene un poder purificador. Produce un periodo liminal que diluye el tiempo, y al ser despojados de sus uniformes, del número que los despersonaliza, los prisioneros retornan a una hermandad primigenia, a su condición humana en su más cruda desnudez ${ }^{18}$.

La lluvia es una evasión, un intento desesperado por recuperar la libertad perdida, la infancia, la memoria, en un mundo que no es tanto "físico como un paisaje moral" (Paz 133). Gracias a la lluvia, los

$17 \mathrm{Al}$ entrar al cuarto de duchas: "Nadie habla entonces, y todos transitamos por los mejores momentos de nuestro pasado hasta que nos muerde las entrañas la corneta que llama al rancho de las seis y despertamos a esta realidad de la prisión." (Diario de Lecumberri, 34).

18 "El valor positivo de la obra de Mutis aparece en la singular vinculación que existe entre el recuerdo y el amor, que hace aparecer a éste, viniendo del pasado, como una epifanía salvadora e intacta”. (Morales 270). 
personajes son conducidos a "una especie de limbo atemporal en el que la memoria de lo vivido se decanta [...]" (Canfield 302). Este vano intento de reconstruir un orden, conecta la lluvia con la idea del quehacer poético que tiene Mutis. Para el autor, la poesía intenta una empresa imposible ${ }^{19}$, recuperar la memoria, el recuerdo de una infancia y paraísos perdidos. Al fin y al cabo "en dondequiera que se viva, como se quiera que se viva, siempre se es un exiliado. Somos exiliados de nuestra infancia, de nuestra vida misma" (Norma). La poesía, aunque apremiante, es el inútil afán de reconstruir el orden a través de la palabra. Como bien señala Palencia-Roth, para Mutis: "words cannot possibly capture reality, they can be only an imitation or substitute, and yet the poet has not alternative: he must try to express the inexpressible" (369):

La poesía substituye, la palabra substituye, el hombre substituye, los vientos y las aguas substituyen...

la derrota se repite a través de los tiempos iay, sin remedio! ("Los trabajos perdidos", Summa... 60).

En referencia a la obra de Mutis, Hosiasson señala que:

Sin esperar nada, su literatura profesa una enorme fe en la naturaleza, poderosa e implacable frente a la nula capacidad humana para la felicidad. Paradójicamente, es a partir de esa derrota cómo su mundo poético fructifica y se expande. Si la poesía no sirve para nada, su inutilidad la construye y justifica (337).

Y es que para Álvaro Mutis, la poesía no es otra cosa que la desesperanzadamente fallida aunque inevitable tarea de dar sentido en palabras, de nombrar este mundo fragmentado y carente de significado $^{20}$.

19 Como afirma Mutis en una entrevista, “Todo poema es la constatación de un absoluto fracaso [...] La palabra sólo sirve como un oscuro signo borroso, de algo que quiero y necesito que permanezca: una imagen, un estado de ánimo, una emoción, una constatación de una verdad." (Sefamí 182). "De nada vale que el poeta lo diga... el poema está hecho desde siempre.” ("Los trabajos perdidos", Summa... 61).

20 Hablando de Maqroll, Martha Canfield señala que él "busca afanosamente un sentido dentro del 'desorden' [...] en el que se mueve." (302). 


\section{Conclusiones}

A lo largo de este ensayo he intentado señalar que la lluvia-como lo serían el río y el mar-- no es un mero elemento del paisaje en la obra de Mutis. Ella compone un complejo universo que condensa dos grandes polos de significación. Debido a su incesante repetición, la lluvia se asocia con el desgaste y el sin sentido de la vida ${ }^{21}$. Al mismo tiempo, la lluvia posee un efecto purificador que lava las miserias humanas. Ella, no obstante, no sólo es símbolo. Ella posee también un carácter ritual y, por tanto, actúa. La lluvia permite conectarse con el pasado y escapar de la fragmentación del presente. Este intento de crear orden en el sinsentido del caos, conecta a la lluvia con la idea que Mutis tiene de la poesía.

De alguna manera, la lluvia sería el equivalente vertical del río. Mientras el río es la corriente horizontal que permite el desplazamiento espacial -el páramo andino, la tierra caliente, la selva, las marismas, el mar y viceversa--, la lluvia logra conectar presente con pasado en una travesía temporal.

\section{Referencias bibliográficas}

Balza, Jorge (1991): "Álvaro Mutis en una sociedad imaginaria”. Palabra suelta 12; pp. 6-9.

Canfield, Martha L. (2001): "De la materia al orden: La poética de Álvaro Mutis". Escritos de y sobre Alvaro Mutis: Caminos y encuentros de Maqroll el Gaviero. Javier Ruiz ed; pp. 283-309.

Cobo Borda, Juan Gustavo (1998): Para leer a Álvaro Mutis. Bogotá: Planeta Colombiana Editorial.

Hernández, Consuelo (1996): Álvaro Mutis: Una estética del deterioro. Caracas, Monte Ávila Editores Latinoamericana. 1996.

Hosiasson, Laura Janina (2001): "La poesía desencantada de Álvaro Mutis”. Portella, Javier Ruiz ed; pp. 335-337.

21 No proponemos que la lluvia sea la única imagen que represente estas cualidades. Antes bien, la obra de Mutis está teñida por este pesimismo, y la lluvia no sería otra cosa que uno de los materiales que usa para expresar esa arcana verdad de la brevedad e inutilidad de la existencia humana. 
Morales Saravia, José (1994): “Poesía y prosa en Álvaro Mutis.” En: Karl Kohut (ed). Literatura colombiana hoy: Imaginación y barbarie. Frankfurt; Vervuert; pp. 265-277.

Mutis, Álvaro (1999): Diario de Lecumberri. La muerte del estratega. Narraciones, prosas y ensayos. México D.F.; Fondo de Cultura Económica.

Madrid; Alfaguara.

(2001): Empresas y tribulaciones de Maqroll el gaviero.

(1995): Summa de Maqroll el gaviero. Poesía 1948-1988. 2da reimpresión. México D.F.; Fondo de Cultura Económica.

NORMA, Grupo Editorial . Álvaro Mutis. http://www.norma.com/autores.asp?IdAutor $=360 \#$ frases, Noviembre 10, 2002.

Palencia-Roth, Michael (2002): "Álvaro Mutis." Latin American Writers. Supplement I. Ed. Carlos A. Solé, Nueva York: Charles Scribner's Sons.

Paz, Octavio (1967): "Los hospitales de ultramar". En: Summa de Maqroll el gaviero. Poesía 1948-1988. Álvaro Mutis. México D.F.; FCE; pp. 9-12.

Sefamí, Jacobo (1999): “Maqroll, la vigilancia del orden”. En: De la imaginación poética: Conversaciones con Gonzalo Rojas, Olga Orozco, Álvaro Mutis y José Kozer. Caracas: Monte Ávila Editores Latinoamericana; pp. 171-228. 